\title{
Secretion of intravenously administered antibiotics in gastric juice: Implications for management of Helicobacter pylori
}

\author{
S J O Veldhuyzen van Zanten, J Goldie, J Hollingsworth, C Silletti, H Richardson, \\ R H Hunt
}

\begin{abstract}
Aims: To study whether differences in eradication rates of antibiotics may be explained by differences in secretion of antibiotics in gastric juice.

Methods: A single intravenous dose of either ampicillin $500 \mathrm{mg}$, erythromycin $500 \mathrm{mg}$, or metronidazole $500 \mathrm{mg}$ was administered to four healthy Helicobacter pylori negative volunteers on different days. Antibiotic concentrations were measured in gastric juice before and every 10 minutes after administration of the drug for two hours and after one hour in serum.

Results: No ampicillin was detected in gastric juice. Erythromycin concentrations in gastric juice showed considerable individual variation and reached maximum concentrations of $2 \cdot 2-4 \cdot 8 \mathrm{mcg}$ / $\mathrm{ml}$ between 30 and 80 minutes after dosing. Metronidazole concentrations in gastric juice showed much less individual variation and maximum concentrations of $5-6 \mathrm{mcg} / \mathrm{ml}$ were reached within 30 minutes and remained high during the study period.
\end{abstract}

Conclusion: Metronidazole and erythromycin are secreted across the gastric mucosa, but ampicillin is not.

The discovery of Helicobacter pylori and its close association with chronic active gastritis and peptic ulcer disease has led to an active interest in trials of antibiotic treatment to eradicate the organism. It is clear that eradication is difficult to achieve, ${ }^{12}$ that recrudescence of the organism will occur if suppression rather than eradication is achieved, ${ }^{3}$ and that antibiotic monotherapy is not very effective. ${ }^{24}$ Furthermore, the in vitro susceptibility of a therapeutic agent does not necessarily predict its in vivo effectiveness. ${ }^{5}$ For example, although erythromycin has low minimum inhibitory concentrations $\mathrm{MIC}_{50}$ and $\mathrm{MIC}_{90}$ values and is effective in combination with other compounds, it was not effective as a single agent in eradicating $H$ pylori. ${ }^{6}$ It has been suggested that the inability of antimicrobial agents to achieve sufficiently high concentrations in the gastric pits contributes to poor eradication rates. ${ }^{?}$

We studied the secretion in gastric juice of intravenously administered ampicillin, erythromycin, and metronidazole in healthy volunteers to investigate whether differences in the ability to secrete these compounds could help explain the clinical findings.

\section{Methods}

Four healthy volunteers (age 21-25 years) participated in the study. They all underwent an upper gastrointestinal endoscopy and they were $H$ pylori negative by histological examination and culture of antral biopsy specimens. Participants were studied on three different days, one for each of the three drugs which were administered in random order. There were at least two washout days between study days. On the morning of each study day, after an overnight fast, a nasogastric tube was passed into the stomach and left in place for the three hours of the protocol. Initial gastric contents were aspirated and discarded. Gastric juice was aspirated for 30 minutes before infusion of the antibiotic, at the time of infusion, and then every 10 minutes for another two hours. Gastric juice $\mathrm{pH}$ concentrations were determined for each sample throughout the study.

The following drugs were given intravenously as a single bolus of $250 \mathrm{cc}$, in random order, on each of the three study days: ampicillin $500 \mathrm{mg}$; erythromycin 500 $\mathrm{mg}$; and metronidazole $500 \mathrm{mg}$. Serum concentrations of these drugs were measured one hour after infusion of each drug. Aliquots of gastric juice and serum were stored in ice and measurements were done in triplicate. Bioassay methods were used for measuring drug concentrations of ampicillin ${ }^{8}$ and erythromycin'; metronidazole measurements were performed using an HPLC (high power liquid chromatography) (Beckman) technique. ${ }^{11}$ In one patient erythromycin concentrations were uninterpretable because gastric juice was mixed with macroscopically visible bile. Results remained uninterpretable when the bioassay was repeated with Streptococcus faecalis, which is resistant to bile, instead of Micrococcus luteus which is normally used for the assay.

The research protocol was approved by the ethics committee at McMaster University Medical Centre and informed written consent was obtained from each volunteer. 
Figure 1 Erythromycin concentrations.

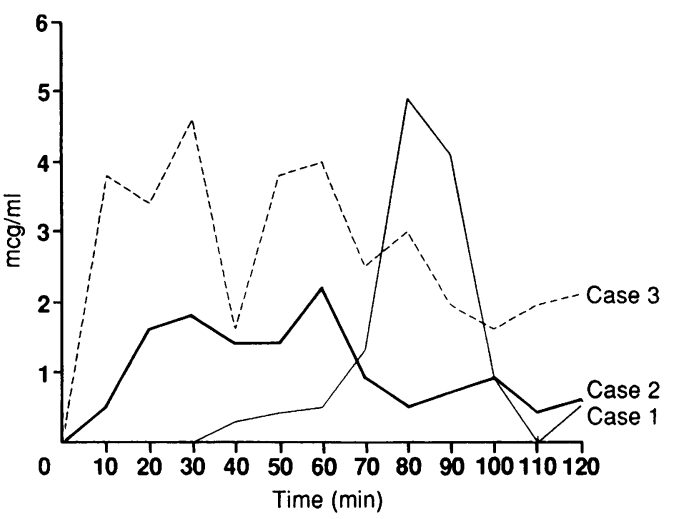

Results

Upper gastrointestinal endoscopies in all four subjects were normal and no $H$ pylori organisms were identified on histology or by culture. All subjects had normal basal acid profiles with a fasting gastric juice $\mathrm{pH}$ ranging from $1 \cdot 47$ to $2 \cdot 15$.

Ampicillin: In none of the four subjects was any ampicillin detected in gastric juice during the two hours following administration of the drug. Serum ampicillin concentrations one hour after intravenous administration were $4.8,4.9,4.9$ and $5 \cdot 1 \mathrm{mcg} / \mathrm{ml}$, respectively.

Erythromycin: Figure 1 shows the results of erythromycin measurements in gastric juice in three subjects. Erythromycin concentrations were uninterpretable in one patient because gastric juice was mixed with macroscopically visible bile. Results remained uninterpretable when the bioassay was repeated with $S$ faecalis, which is resistant to bile, instead of $M$ luteus which is normally used for the assay. There were considerable individual variations in the results and erythromycin appeared in gastric juice soon after intravenous infusion in two, and at 30 minutes in the third subject. Peak concentrations were reached between 30 and 80 minutes. The concentration of erythromycin in gastric juice started to fall during the second hour in each subject. Serum erythromycin concentrations one hour after intravenous administration were $2 \cdot 2,2 \cdot 8$, and $4 \cdot 8 \mathrm{mcg} / \mathrm{ml}$. Metronidazole: Figure 2 shows the results of metronidazole secretion in gastric juice. Metronidazole appeared at 10 minutes and peak gastric juice concentrations were obtained at 30-50 minutes and only declined slightly

Figure 2 Metronidazole concentrations. during the two hours of the study. Serum concentrations were $5 \cdot 2,5 \cdot 5,6 \cdot 4$ and $6 \cdot 6 \mu \mathrm{g} / \mathrm{ml}$ at one hour after dosing.

\section{Discussion}

Our results show that after intravenous administration erythromycin and metronidazole are secreted in gastric juice. Despite adequate serum ampicillin concentrations it was not detected in the gastric juice. We are unaware of any other study that has shown active secretion of erythromycin or metronidazole in the human stomach. We were surprised not to find any ampicillin in the gastric juice because it is generally stable in the presence of gastric acid. ${ }^{12} \mathrm{Up}$ to $55 \%$ of an oral dose of ampicillin is absorbed, indicating that it can pass intact through the stomach. ${ }^{12}$ It is therefore unlikely that ampicillin was broken down by gastric acid and that this was the reason it could not be detected by the bioassay. Ampicillin may not be secreted by or pass through the gastric mucosa because of certain pharmocokinetic properties, but this was not assessed in our study.

McNulty et al found inhibitory concentrations of activity against $H$ pylori following an oral dose of amoxycillin $500 \mathrm{mg}$ in endoscopic biopsy specimens from the gastric antrum, but it is unclear whether the tissue concentrations were achieved by local absorption from the gastric lumen or by active secretion through the gastric mucosa. ${ }^{13}$

In one subject there was interference with the measurement of erythromycin concentrations caused by the presence of bile, which is a recognised problem. ${ }^{814}$ Although erythromycin and metronidazole were both secreted in the gastric juice, there were differences between the two compounds. Erythromycin showed more individual variation; the average peak concentration was reached later than metronidazole and gastric juice concentrations fell in the second hour of the study in contrast to metronidazole where concentrations tended to be maintained. Considerable variations in mucosal concentrations of erythromycin were also found in McNulty's study, but metronidazole was not investigated. ${ }^{13}$

Clinical experience has shown that ampicillin as a single agent can eradicate $H$ pylori in about $25 \%$ of cases, ${ }^{115}$ whereas metronidazole and erythromycin can not. ${ }^{612}$ McNulty et al have shown that the influence of $\mathrm{pH}$ on antimicrobial activity may have an important role: the $\mathrm{MIC}_{90}$ (in $\mathrm{mg} / \mathrm{l}$ ) of ampicillin increased from 0.06 at $\mathrm{pH} 7.5$ to 0.5 at $\mathrm{pH} 5 \cdot 5$. For erythromycin these values were 0.06 at $\mathrm{pH} 7.5$ and 8.0 at $\mathrm{pH} 5.5$. The values for metronidazole, which has weak in vitro inhibitory activity with an $\mathrm{MIC}_{50}$ of $0.5-1.0$ and $\mathrm{MIC}_{90} 4 \cdot 0-8 \cdot 0,{ }^{16}{ }^{17}$ did not show any change and remained stable at $2 \cdot 0$. Although the effects of further lowering the $\mathrm{pH}$ were not studied, as $H$ pylori does not grow well at lower $\mathrm{pH}$, it is certainly possible that the MIC may increase further at the more acid $\mathrm{pH}$ concentrations of $1 \cdot 0-2 \cdot 0$ that were present in our study and are commonly found in the stomach. Other 
explanations for the differences between in vitro and in vivo behaviour of antibiotic agents against $H$ pylori are changes in structure of the compound by acid, poor mucus penetration, and differences in absorption or secretion in the stomach. $^{2}$

Our study was limited by examining only the effect of a single intravenous dose of each agent in healthy volunteers. It is possible that the topical effect or local absorption of these compounds is important for clinical efficacy. Our results would support a topical effect or absorption in the stomach as possible reasons for the clinical effect of ampicillin rather than secretion across the mucosa. Whether the presence of inflammation in patients with gastritis influences the secretion and absorption of antibiotics in the stomach is not known.

In conclusion, we have shown that in healthy volunteers the intravenous administration of metronidazole and erythromycin results in secretion of these compounds in high concentrations in gastric juice whereas for ampicillin this does not seem to be the case.

1 Rauws EAJ, Langenberg W, Houthoff HJ, Zanen HC, Tytgat GNJ. Campylobacter pyloridis-associated chronic active antral gastritis. A prospective study of its prevalence and the effects of antibacterial and antiulcer treatment. Gastroenterology 1988;94:33-40.

2 Hirschl AM, Pletschette M. Antibiotic treatment of Campylobacter pylori infection. In: Rathbone BJ, Heatley RV, eds. Campylobacter pylori and gastroduodenal disease.

3 Langenberg W, Rauws EAJ, Widjojokusomo A, Tytgat GNJ, Zanen HC. Identification of Campylobacter pyloridis isolates by restriction endonuclease DNA analysis. J Clin Microbiol 1986;24:414-7.

4 Borsch G, Mai U, Muller KM. Monotherapy or polychemotherapy in the treatment of Campylobacter pylori related gastroduodenal disease. Scand J Gastroemterol 1988;23:101-6.

5 McNulty CAM. Bacteriological and pharmacological basis for the treatment of Campylobacter pylori infection. In Rathbone BJ, Heatley RV, eds. Campylobacter pylori and gastroduodenal disease. Oxford: Blackwell Scientific Publications, 1989:209-16.

6 McNulty CAM, Gearty JC, Crump B, et al. Campylobacte pyloridis and associated gastritis: investigator blind placebo controlled trial of bismuth salicylate and erythromycin ethylsuccinate. $\mathrm{Br}$ Med J 1986;293:645-9.

7 McNulty CAM. The treatment of Campylobacter associated gastritis. Am J Gastroenterol 1987;82:245-7.

8 Sutherland R, Rolinson GN. Methods of antibiotic assays: penicillins. In: Reeves DS, Philips I, David Williams J, Wise R. eds. Laboratory methods in antimicrobial chemotherapy. Edinburgh: Churchill Livingstone, 1978:171-8.

9 therapy. Edinburgh: Churchill Livingstone, 1978:171-8. Reeves DS, Philips I, David Williams J, Wise R, eds. Laboratory methods in antimicrobial chemotherapy. dinburgh: Churchill Livingtone, 1978.208-11.

10 Gibson RA, Lattanzio L, McGee H. Optimised liquidchromatographic determination of metronidazole and its metabolites in plasma. Clin Chem 1984;30:784-7.

11 Rona K, Gachalyi B. Simple liquid chromatographic method for determination of ornidazole and metronidazole in human serum. J Chromatogr 1987;420:228-30.

12 American Society of Hospital Pharmacists. Ampicillin. In: McEvoy GK, ed. American Hospital Formulary Service 91. 280-1.

13 McNulty CAM, Dent JC, Ford GA, Wilkinson SP. Inhibitory antimicrobial concentrations against nhibitory antimicrobial concentrations against Campylobacter pylori in gast

14 Edberg SC. The measurement of antibiotics in human body fluids: techniques and significance. In: Lorian V, ed. Antibiotics in laboratory medicine. 2nd ed. Baltimore: Williams \& Wilhius, 1986:386

15 Bayerdorffer E, Ottenjann R. The role of antibiotics in Campylobacter pylori associated peptic ulcer disease. Scand J Gastroenterol 1988;23:93-100.

16 McNulty CAM, Dent J, Wise R. Susceptability of clinical isolates of Campylobacter pyloridis to 11 antimicrobial agents. Antimicrob Agents Chemother 1985;28:837-8.

17 Goodwin CS, Blake P, Blincow E. The minimum inhibitory and bactericidal concentrations of antibiotics and anti-ulcer agents against Campylobacter pyloridis. anti-ulcer agents against Campylobacter 